\title{
ANALISIS PENGGUNAAN ANTIBIOTIKA DENGAN METODA ATC/DDD DI RUMAH SAKIT SWASTA KAB KARAWANG
}

${ }^{1}$ Diany Astuti, M.Farm., Apt

${ }^{2}$ Maya Arfania, M.Sc., Apt

\author{
${ }^{1}$ Prodi Farmasi Fakultas Teknologi dan Ilmu Komputer Universitas Buana Perjuangan \\ Karawang (dianyastuti@ubpkarawang.ac.id) \\ ${ }^{2}$ Prodi Farmasi Fakultas Teknologi dan Ilmu Komputer Universitas Buana Perjuangan \\ Karawang (maya.arfania@ubpkarawang.ac.id)
}

\begin{abstract}
ABSTRAK
Resistensi antimikroba merupakan kejadian yang rentan terjadi pada masa ini yang salah satunya disebabkan oleh penggunaan antimikroba yang tidak bijak. Untuk memerbaiki data resistensi terhadap mikroba diperluka suatu upaya untuk mengendalikan terjadinya resistensi antimikroba. Kegiatan yang dapat dilakukan salah satunya adalah menggunakan antimikroba dengan bijak yang dapat dilakukan dengan melakukan evaluasi penggunaan antimikroba kuantitatif dan kualitatif secara berkala. Penelitian dilakukan di ruang rawat inap dewasa salah satu rumah sakit swasta di Kabupaten Karawang dengan kegiatan kajian analisis tingkat pemakaian antimikroba dengan metoda sesuai dianjurkan WHO ATC/DDD menggunakan aplikasi AMC tool. Penelitian dilakukan dengan metoda deskripsi analitis dengan purposive sampling pada 165 pasien dengan 141 () menggunakan terapi dengan antimikroba dan 24() menggunakan terapi non antimikroba. Hasil penelitian menunjukkan nilai antimicroba comsumtion index (ACI) sebesar 121, 57DDD/100 hari rawat dengan pemakaian jenis antimikroba tertinggi adalah golongan sefalosporin ceftriaxone 67,851 DDD/hari rawat, etambutol 16,23 DDD/hari rawat $(13,36 \%)$ dan sefuroksim $11,89 \mathrm{DDD} /$ hari rawat $(9,79 \%)$
\end{abstract}

Kata Kunci : resistensi antimikroba, ATC/DDD, Antibiotika, DDD/100 hari rawat, Sefalosporin

\begin{abstract}
Antimicrobial resistance is an incident that occurred during this vulnerable, one of which was caused by Unwised use of an antimicrobial. To repair a resistance to microbial data need an effort to control the occurrence of antimicrobial resistance. Programs that can be done by using antimicrobial wisely by doing an evaluation of antimicrobial use quantitative and qualitative periodically. Research conducted in adult inpatient one private hospital in Karawang. Study of antimicrobial usage level analysis method in accordance with recommended WHO ATC/DDD using AMC application tool. Methode of research analytical description with purposive sampling on 165 patients with 141 patients using therapy with antimicrobial and 24 patient use a non therapeutic antimicrobials. The results showed the value antimicroba comsumtion index (ACI) of 121,
\end{abstract}


57DDD/bed days and ceftriaxone 67,851 DDD/bed days (55,86\%), ethambutol 16,23 DDD/bed days ( $13,36 \%)$ and cefuroxime 11,89 DDD/bed days (9,79\%) as the highest used antimicroba

Keywords : antimicrobial resistance, ATC/DDD method, antibiotic, DDD/100 bed days, cephalosporins

\section{PENDAHULUAN}

Antibiotika merupakan golongan obat yang banyak digunakan dalam terapi penyakit baik di Negara maju maupun Negara berkembang. Data pengadaan obat untuk golongan antibiotikaa di sarana pelayanan kesehatan menunjukkan bahwa antibiotikaa merupakan golongan obat yang menghabiskan lebih dari seperempat anggaran. (Mahmudah, Sumiwi, \& Hartini, 2016) Hasil penelitian Antimicrobial resistance in Indonesia : Prevalence and Prevention (AMRIN Study) tahun 2005 menyatakan bahwa masalah resistensi antimikroba merupakan masalah kesehatan yang penting di Indonesia karena ditemukannya masalah resistensi antimikroba sudah terjadi di Indonesia.

Peningkatan kejadian dan penyebaran mikroba yang resisten terhadap antimikroba di rumah sakit salah satunya disebabkan oleh penggunaan antibiotikaaa yang tidak bijak dan rendahnya ketaatan terhadap kewaspadaan standar. Strategi yang digunakan untuk pengendalian dengan cara penggunaan antibiotikaa secara bijak dan peningkatan ketaatan terhadap prinsip pencegahan dan pengendalian infeksi. (Kementrian Kesehatan RI, 2015) Kegiatan penggunaan antibiotikaa secara bijak salah satunya adalah dengan melaksanakan surveilans pola penggunaan antibiotikaa, pola mikroba penyebab infeksi dan kepekaannya terhadap antibiotikaa serta melakukan pelaporan secara berkala. Evaluasi yang dilakukan terhadap program pengendalian antimikroba dilakukan dengan cara evaluasi penggunaan antibiotikaa berupa audit penggunaan antibiotikaa secara kuantitatif dan kualitatif serta pemantauan atas munculnya mikroba multiresisten.

Untuk dapat mengkaji penggunaan antibiotikaa diperlukan suatu metoda khusus yang terstandarisasi agar setiap antibiotikaa yang dikaji dapat dibandingkan satu sama lainnya. Hal ini karena penggunaan setiap antibiotikaa mempunyai dosis harian yang berbeda setiap pemberian ke pasien. WHO menetapkan metoda spesikik dan terstandarisasi untuk klasifikasi penggunaan antibiotikaa dan pengukuran kuantitas antibiotikaa yaitu metoda Anatomical Therapeutic Chemical (ATC) Clasification untuk klasifikasi antibiotikaa dan metoda pengukuran penggunaan antibiotikaa menggunakan metoda Defined Daily Dose 
(DDD)/ 100 patient days. Metoda Drug Utilization 90\% (DU 90\%) merupakan metoda yang menunjukkan pengelompokan obat yang termasuk dalam kategori $90 \%$ penggunaan yang sering digunakan bersama dengan analisis penggunaan obat ATC/DDD. Penilaian terhadap obat yang masuk ke dalam segmen $90 \%$ diperlukan untuk menekankan segmen obat yang dikaji kaitannya dengan evaluasi pengendalian penggunaan dan perencanaan pengadaan obat. (Mahmudah, Sumiwi, \& Hartini, 2016)

Analisis penggunaan antibiotikaa yang dilakukan pada salah satu rumah sakit di Turki pada tahun 2011 menunjukkan nilai Antimicrobial Compsumtion Index (ACI) 55,1 DDD/100 hari rawat. (Sozen, et al., 2013) Penelitian lain yang dilakukan di Italy oleh Vaccheri et al pada salah satu rumah sakit pendidikan menunjukkan adanya peningkatan penggunaan antibiotika dari nilai ACI 64,9 DDD/100 hari rawat pada tahun 2002 menjadi 76,7 DDD/100 hari rawat di tahun 2004. Pola konsumsi antibiotika yang dilakukan di RSK ST Vincentius Surabaya di tahun 2006 diperoleh nilai ACI sebesar 80,2 DDD/100 hari rawat dengan golongan antibiotika yang paling banyak digunakan adalah sefalosporin dan karbapenem (33,2\%), penisilin $(28,1 \%)$ dan kuinolon (19\%). (Herawati, 2008) Penelitian yang dilakukan dibagian bedah digestif di salah satu rumah sakit di Bandung antibiotika yang paling banyak digunakan adalah seftriakson sebesar 8,77 DDD/100 hari rawat dan antibiotikaa yang masuk dalam segmen DU 90\% yaitu seftriakson, metronidazole, sefiksim, sefepim, siprofloksasin dan meropenem. (Mahmudah, Sumiwi, \& Hartini, 2016)

Pola penggunaan antibiotikaa di rumah sakit berkorelasi dengan data penyakit yang ditangani oleh rumah sakit dan sekaligus juga dapat digunakan untuk mengendalikan jumlah persediaan perbekalan antibiotika di rumah sakit.

Tujuan penelitian ini adalah untuk mengetahui nilai ACI dalam satuan DDD/ 100 hari rawat dan DU 90\% di salah satu rumah sakit swasta di Kabupaten Karawang sebagai data dasar untuk kegiatan pengendalian resistensi antimikroba dan pengendalian anggaran instalasi farmasi di rumah sakit.

\section{METODE PENELITIAN}

Penelitian ini merupakan penelitian deskriftif analitis dengan purposive samping dan pengambilan data bersifat retrospektif. Penelitian dilaksanakan di salah satu rumah sakit swasta di Kabupaten Karawang. RS ini merupakan rumah sakit tipe C dengan kapasitas 
102 tempat tidur. Rumah sakit ini mempunyai 8 kelompok Staf Medis Fungsional (SMF) yaitu SMF penyakit dalam, SMF anak, SMF Obgyn dan ginekologi, SMF Bedah, SMF Urologi, SMF paru, SMF Kulit dan Kelamin, SMF Gigi, dan SMF Anestesi.

Sumber data diperoleh dari data permintaan obat di rawat inap dewasa bagian peserta Jaminan Kesehatan Nasional (JKN) dan rekam medis pasien, serta data pengeluaran perbekalan antibiotikaa di Instalasi farmasi periode April - Juni 2018. Data yang diperoleh adalah data demografi pasien dan jenis dan jumlah antibiotikaa yang digunakan oleh pasien rawat inap dewasa peserta JKN. Analisa pengunaan antibiotikaa menggunakan $A M C$ tool yang dikelola oleh WHO Collaborating Centre for Drug Statistics Methodology yang bertempat di Oslo, Norwegia. AMC tool adalah program yang digunakan untuk mengkalkulasi komsumsi antimikroba menggantikan program serupa sebelumnya $A B C$ Calc. $A M C$ tool yang digunakan adalah $A M C$ tool version 1.5.0 yang mengacu pada WHO ATC/DDD index tahun 2015. (WHO, 2015)

\section{Kriteria Inklusi}

Kriteria inklusi pada penelitian ini adalah :

1. Lembar permintaan obat untuk pasien rawat inap dewasa usia 18-60 tahun dan usia $>60$ tahun

2. Lembar permintaan obat mengandung antibiotikaa sistemik

\section{Kriteria Ekslusi}

1. Lembar permintaan untuk pasien anak usia $<18$ tahun

2. Lembar permintaan obat tidak mengandung antibiotikaa

3. Lembar permintaan obat mengandung antibiotikaa non sistemik

\section{PEMBAHASAN}

Data hasil pengkajian penggunaan antibiotika di rawat inap dewasa dengan jenis pasien dari asuransi JKN untuk periode April-Juni 2018 diperoleh data sebanyak 183 dokumen, 18 data tidak lengkap, sehingga data yang dikaji sebanyak 165 buah data. Data yang diperoleh menunjukkan bahwa $141(85,45 \%)$ pasien mendapatkan terapi dengan antibiotika untuk berbagai kasus dan 24 (14,55\%). Data pasien yang mendapatkan terapi dengan antibiotika dengan kelompok usia 18-45 tahun $76(53,90 \%)$ pasien terdiri dari 36 $(47,37 \%)$ pasien laki laki dan $40(52,63 \%)$ perempuan, usia 45-60 tahun $41(29,08 \%)$ 
terdiri dari $22(53,66 \%)$ laki laki dan $19(46,34 \%)$ perempuan dan kelompok usia > 60 tahun $24(17,02 \%)$ terdiri dari $19(79,17 \%)$ laki laki dan 5(20,83\%) perempuan. (Tabel 1)

Tabel 1 Data Demografi

\begin{tabular}{|l|r|r|}
\hline \multirow{2}{*}{ kriteria } & \multicolumn{2}{|c|}{ jumlah } \\
\cline { 2 - 3 } & $\mathrm{n}$ & \multicolumn{1}{|c|}{$\%$} \\
\hline data awal & 183 & 100,00 \\
lengkap & 165 & 90,16 \\
tidak lengkap & 18 & 9,84 \\
& & \\
\hline Terapi & & \\
antibiotik & 141 & 85,45 \\
non antibiotik & 24 & 14,55 \\
& & \\
\hline Usia & & \\
$18-45$ tahun & 76 & 53,90 \\
pria & 36 & 47,37 \\
wanita & 40 & 52,63 \\
\hline $45-60$ tahun & 41 & 29,08 \\
pria & 22 & 53,66 \\
wanita & 19 & 46,34 \\
\hline$>60$ tahun & 24 & 17,02 \\
pria & 19 & 79,17 \\
wanita & 5 & 20,83 \\
\hline
\end{tabular}

Penggunaan antibiotika selama periode pengamatan diolah dengan AMC tool sesuai guidelines WHO untuk pengkajian konsumsi antibiotika dengan metoda ATC/DDD. Hasil analisis menunjukkan bahwa nilai Antimicroba consumtion index (SCI) untuk penelitian ini adalah $121,57 \mathrm{DDD} / 100$ hari rawat untuk anti infeksi dan anti parasit 1,218 DDD/100 hari rawat. Hasil ini menunjukkan bahwa nilai pemakaian antibiotika sistemik rumah sakit ini masih lebih tinggi dibandingkan dengan hasil penelitian yang dilakukan Sozen et al pada tahun 2013 di Turki yaitu sebesar 55,21 DDD/100 hari rawat. Hasil ini juga masih lebih tinggi jika dibandingkan dengan penelitian serupa yang dilakukan di Itali terhadap rumah sakit pendidikan yang dilakukan oleh Vaccheri et al tahun 2004 yaitu 76,7 DDD/100 hari rawat. Nilai ACI hasil penelitian dibandingkan dengan penelitian serupa yang dilakukan di Surabaya menunjukkan nilai pemakaian antibiotika hasil pengamatan masih lebih tinggi yaitu 80,22 DDD/100 hari rawat. 
Tabel 2 Daftar Nilai Pemakaian Antibiotika Berdasarkan Metoda ATC/DDD

\begin{tabular}{|l|l|r|r|}
\hline \multicolumn{1}{|c|}{ kode } & \multicolumn{1}{|c|}{ Jenis Antibiotika } & DDD & \multicolumn{1}{c|}{ ACI } \\
\hline J01DC & 2nd generation cephalosporins & & 11,896 \\
J01DC02 & cefuroxime & 36,917 & \\
\hline J01DD & 3rd generation cephalosporins & & 67,857 \\
J01DD04 & ceftriaxone & 209 & 10,958 \\
J01DD07 & ceftizoxime & 33,75 & 0,747 \\
J01DD08 & cefixime & 7,3 & 25 \\
J01DD12 & Cefoperazone & & \\
\hline J01M & Quinolone antibacterial & 10 & 354 \\
J01MA02 & ciprofloxacin & 10 & 3,247 \\
J01MA13 & levofloxacin & & 3,247 \\
J01X & Other Antibacterial & 7,167 & \\
J01X & metronidazol & 58,05 & 2,327 \\
\hline J04 & antimicobacterial & 4,05 & 18,847 \\
J04AB02 & Rifampicin & 4 & 1,315 \\
J04AK01 & pyrazinamide & 50 & 1,299 \\
J04AK02 & ethambutol & 16,234 \\
\hline
\end{tabular}

Tabel 3 Nilai DU90\%

\begin{tabular}{|l|l|r|r|r|r|}
\hline \multicolumn{1}{|c|}{ kode } & \multicolumn{1}{|c|}{ Jenis Antibiotika } & DDD & \multicolumn{1}{c|}{ ACI } & \multicolumn{1}{c|}{$\%$} & DU 90\% \\
\hline J01DD04 & leftriaxone & 209 & 67,857 & 55,86 & 67,86 \\
J04AK02 & ethambutol & 50 & 16,234 & 13,36 & 16,23 \\
J01DC02 & cefuroxime & 36,917 & 11,896 & 9,79 & 11,90 \\
J01DD07 & ceftizoxime & 33,75 & 10,958 & 9,02 & 10,96 \\
J01MA02 & ciprofloxacin & 10 & 3,247 & 2,67 & 3,25 \\
J01MA13 & levofloxacin & 10 & 3,247 & 2,67 & 3,25 \\
J01DD12 & Cefoperazone & 7,25 & 2,354 & 1,94 & 2,35 \\
J01X & metronidazol & 7,167 & 2,327 & 1,92 & 2,33 \\
J04AB02 & Rifampicin & 4,05 & 1,315 & 1,08 & 1,32 \\
J04AK01 & pyrazinamide & 4 & 1,299 & 1,07 & 1,30 \\
J01DD08 & cefixime & 2,3 & 0,747 & 0,61 & 0,75 \\
\hline Total & & & 121,481 & 100 & 121,481 \\
\hline
\end{tabular}

Hasil pengamatan menunjukkan bahwa jenis antibiotika yang digunakan tertinggi adalah sefalosporin generasi ke 3 yaitu seftriakson dengan nilai ACI 67,857 DDD/100 hari rawat $(55,86 \%)$. Untuk jenis antibiotika yang sering dan menduduki pemakaian tertinggi baik penelitian yang dilakukan oleh Sozen di Turki, Vaccheri di Itali, dan untuk di wilayah 
Indonesia penelitian yang dilakukan oleh di Surabaya dan Bandung mendapatkan hasil yang sama yaitu seftriakson. (Tabel 2)

Dari hasil pengamatan diperoleh untuk wilayah Indonesia nilai komsumsi antibiotika tergolong masih tinggi. Walaupun untuk jenis antibiotika yang banyak digunakan adalah sama yaitu antibiotika golongan sefalosporin generasi ketiga.

Penelitian ini dilaksanakan dalam rangka mendapatkan data awal untuk pelaksanaan program pengendalian resistensi antimikroba. Kondisi rumah sakit belum mempunyai suatu tim atau komite yang bertugas untuk mengatur penggunaan antibiotika di rumah sakit.

Berdasarkan data yang diperoleh, diketahui bahwa dari 165 lembar data pengamatan pasien yang mendapatkan terapi antibiotika di ruangan rawat inap dewasa dengan jenis pasien peserta asuransi Jaminan Kesehatan Nasional (JKN) diperoleh $24(14,55 \%)$ lembar data pengamatan yang tidak menggunakan antibiotika sebagai terapinya. Data rekam medis rumah sakit menunjukkan bahwa untuk pasien rawat inap kategori penyakit infeksi thypid berada pada posisi teratas dari daftar 10 penyakit yang dilayani oleh rumah sakit tersebut. (tabel 4)

Tabel 4 Indeks 10 Penyakit Rawat Inap Tahun 2018

\begin{tabular}{|c|l|l|c|}
\hline \multicolumn{5}{|c|}{ Indeks 10 Penyakit RI berdasarkan Data Primer Ina-Cbg's 2018 } & Total \\
\hline 1 & A01.0 & Typhoid fever & 580 \\
\hline 2 & P03.4 & Fetus and newborn affected by caesarean delivery & 467 \\
\hline 3 & A09.9 & Gastroenteritis and colitis of unspecified origin & 289 \\
\hline 4 & 042.9 & Premature rupture of membranes, unspecified & 179 \\
\hline 5 & O33.9 & Maternal care for disproportion, unspecified & 185 \\
\hline 6 & O06.4 & Unspecified abortion, incomplete, without complication & 145 \\
\hline 7 & K40.9 & Unilateral or unspecified inguinal hernia, without obstruction or gangrene & 144 \\
\hline 8 & A16.2 & Tb lung without mention of bact or histological confirm & 125 \\
\hline 9 & 014.1 & Severe pre-eclampsia & 102 \\
\hline 10 & 032.1 & Maternal care for breech presentation & 94 \\
\hline
\end{tabular}

Berdasarkan pada Standar Pelayanan Medis Penyakit Dalam pilihan terapi pada tifoid menggunakan sefalosporin generasi ketiga. Secara garis besar hasil pengkajian pemakaian antibiotika mempunyai kesesuaian dengan standar keilmuannya. Namun penelitian ini tidak melakukan analisis kualitatif pemakaian antibiotika pada setiap kasus yang terjadi di rumah sakit.

Data indeks 10 penyakit rumah sakit untuk rawat jalan menunjukkan bahwa penyakit infeksi bukan menjadi yang terbanyak dalam pelayana rumah sakit. Pelayanan lebih banyak untuk penyakit degeneratif yaitu pelayanan terapi untuk hipertensi. Dengan data ini diperlukan pengkajian lebih dalam untuk pemakaian antibiotika di rawat jalan apakah 
mempunyai korelasi dengan indeks 10 penyakit rawat jalan yang dilayani oleh rumah sakit. (Tabel 5)

Tabel 5 Indeks 10 Penyakit Rawat Jalan Tahun 2018

\begin{tabular}{|c|l|l|c|}
\hline \multicolumn{2}{|c|}{ Indeks 10 Penyakit RJ berdasarkan Data Primer Ina-Cbg's 2018 } & Total \\
\hline 1 & I10 & Essential (primary) hypertension & 132 \\
\hline 2 & K40.9 & Unilateral or unspecified inguinal hernia, without obstruction or gangrene & 137 \\
\hline 3 & A09.9 & Gastroenteritis and colitis of unspecified origin & 142 \\
\hline 4 & E14.9 & Unspecified diabetes mellitus without complications & 143 \\
\hline 5 & R10.4 & Other and unspecified abdominal pain & 170 \\
\hline 6 & H26.9 & Cataract, unspecified & 174 \\
\hline 7 & A01.0 & Typhoid fever & 186 \\
\hline 8 & R50.9 & Fever, unspecified & 225 \\
\hline 9 & A16.2 & Tb lung without mention of bact or histological confirm & 228 \\
\hline 10 & K30 & Dyspepsia & 423 \\
\hline
\end{tabular}

PENUTUP

Kesimpulan dari penelitian ini menunjukkan bahwa komsumsi pemakaian antibiotika di salah satu rumah sakit swasta di Kabupaten Karawang menunjukkan pemakaian yang cukup tinggi (121,57 DDD/100 hari rawat) dibandingkan dengan penelitian sejenis yang dilakukan baik di luar negeri maupun di wilayah Indonesia sendiri. Evaluasi sejenis perlu dilakukan secara periodik untuk menilai keberhasilan program pengendalian resistensi antibiotika.

Untuk dapat melaksanakan pengendalian resistensi antimikroba diperlukan evaluasi kualitatif untuk dapat menilai kerasionalan pemakaian antimikroba di rumah sakit. Data penelitian ini dapat digunakan sebagai dasar untuk pembentukan komite pengendalian resistensi antimikroba di rumah sakit dan menginisiasi penelitian lain yang mendukung dalam program pengendalian antimikroba terutama penelitian kualitatif pemakaian antimikroba.

\section{DAFTAR PUSTAKA}

Herawati, F. (2008). Tinjauan Kuantitas Penggunaan Antibiotik di RSK ST Vincentius A Pailo Surabaya dan Rasionalitas Penggunaan Antibiotik Pada Pasien Pneumonia Nosokomial yang Menjalani Rawat Inap di RSK ST Vincentius A Paulo Surabaya Pada Tahun 2006. Surabaya: Universitas Surabaya.

Kementrian Kesehatan RI. (2015). PMK No 8 tahun 2015 : Program Pengendalian Antimikroba di Rumah Sakit.

Mahmudah, F., Sumiwi, S., \& Hartini, S. (2016). Studi Penggunaan Antibiotik Berdasarkan ATC/DDD dan DU 90 di Bagian Bedah Digestif di Salah Satu Rumah Sakit di Bandung. Jurnal Farmasi Klinik Indonesia, 293-298. 
Sozen, H., Gonen, I., Sozen, A., Kutlucan, A., Kalemci, S., \& Sahan, M. (2013). Application of ATC/DDD Methodology to Evaluate of Antibiotic Use in a General Hospital in Turkey. Annals of Clinical Microbiology and Antimicrobials, 23-29.

WHO. (2015, november 1). Guidelines for ATC Clasification and DDD assignment2015. 